\section{Realidades \\ francesas e \\ brasileiras}

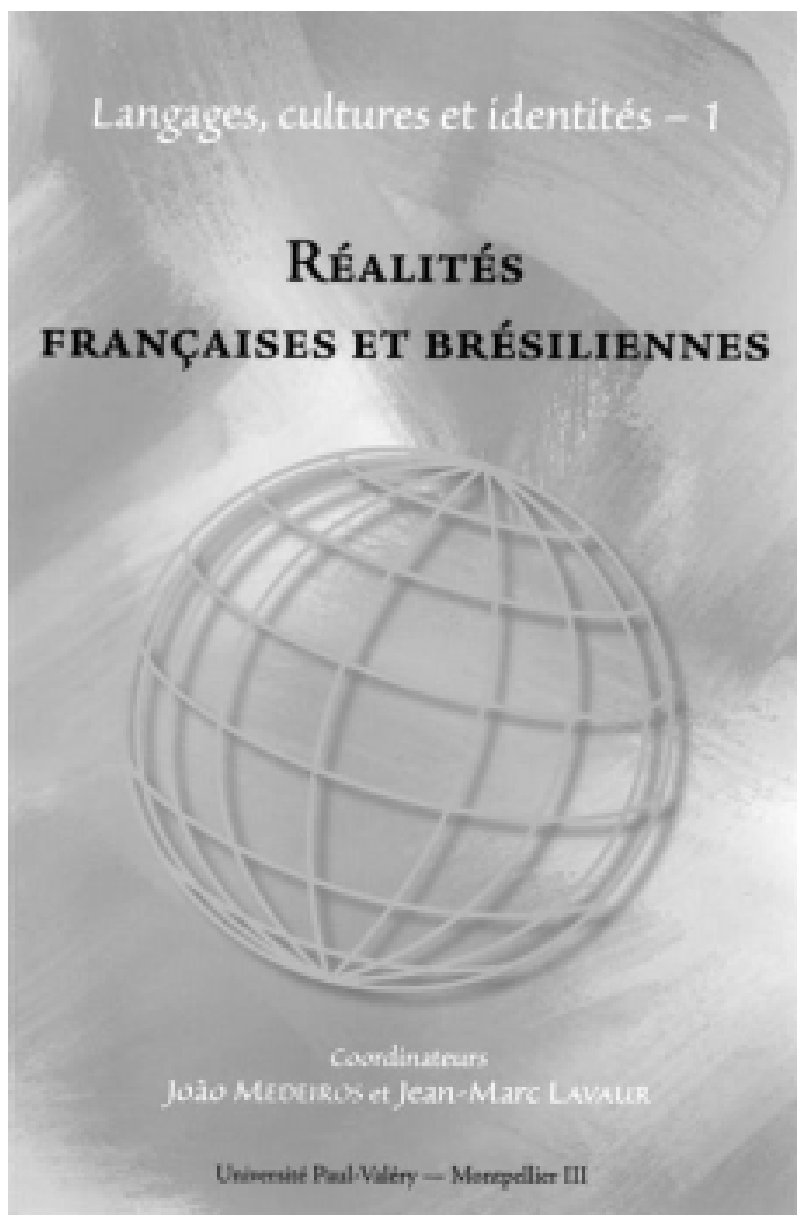

Naiana Pinto Soares

Mestranda em Sociologia / UPV - Montpellier III
Os TEXTOS QUE COMPÕEM esta coletânea associam-se à problemátização de três conceitos que são os fundamentos de toda organização social: a linguagem, a cultura e a identidade. Estes três pilares não são, entretanto, rígidos, mas suscetíveis às mudanças e influências de outros universos simbólicos paralelos. A formação identitária, seja ela individual ou coletiva, é intrinsecamente ligada à alteridade. Em outras palavras, o meu olhar sobre o outro, e o olhar deste sobre mim, é o que determina minha autopercepção e própria construção pessoal. Neste sentido, como imaginar a formação cultural brasileira se não existisse a influência de outros países, como a França? Teria o Brasil emergido de outro modo se tais trocas jamais tivessem existido? E a França, como imaginá-la sem os territórios do além-mar, sem as trocas feitas com outras culturas?

Desde o Brasil Império e, sobretudo a partir de 1822 (abertura da então colônia ao comércio exterior, acontecimento que abre via à independência), a França era considerada como um modelo ideológico resistente. Era o país das artes, das letras, do progresso científico e também do que atualmente considera-se "pseudo-científico", ou seja, as teorias de historiadores como Le Play ou Comte de Gobineau. Estes últimos reivindicavam (entre o fim do século XVIII e os primórdios do século XIX) a superioridade da "raça branca" e justificavam a escravidão por uma suposta hierarquia racial. Todavia, o Brasil, que ficou por muito tempo contemplativo no que diz respeito à cultura européia, questiona-se, aos poucos, sobre sua própria identidade. Os mais tangíveis rastros desta fomentação interior encontram-se na literatura (o naturalismo e o modernismo, por exemplo) nas artes plásticas e mais diretamente no movimento antropofágico. A França, por sua vez, mostra- 
se igualmente consumidora da cultura brasileira, especialmente no que concerne à música, ao esporte e à moda.

O livro em questão é dividido em duas partes: "Realidades brasileiras" e "Realidades francesas", sendo as duas orientadas pelas três temáticas anteriormente mencionadas. João Medeiros ${ }^{1}$ abre o debate abordando a influência européia no Brasil, assim como os diversos movimentos que exprimem a vontade de reapropriação da cultura nacional. Estes movimentos são uma prova da intenção de integrar a inegável herança européia à riqueza do sincretismo étnico-cultural particular ao Brasil. Em seguida, Ruben George Oliven ${ }^{2}$ analisa certas formas de manifestações culturais populares que se tornaram símbolos da identidade nacional. Segundo o autor, o carnaval, o samba, o futebol, o religioso, entre outros, reforçariam a coesão nacional apesar das disparidades e conflitos sociais presentes no cotidiano. No capítulo que segue, Airton Jungblut ${ }^{3}$ trata da transposição das identidades do mundo real ao universo virtual. Jungblut evidencia o comportamento típico dos internautas brasileiros. Estes "malandros" virtuais constituem nada menos do que $80 \%$ dos mais ativos hackers no mundo. No que diz respeito ao mundo material, Isabel C. Moura Carvalho ${ }^{4}$ aborda a questão do militarismo ecológico na juventude brasileira e, segundo sua análise, esta conscientização abre freqüentemente ao portas ao engajamento político. Os dois últimos textos desta primeira parte são dedicados à identidade religiosa no Brasil. O antropólogo Bernardo Lewgoy ${ }^{5}$ fala das especificidades do Espiritismo Kardecista brasileiro, crescente entre os crentes de uma maneira geral e, mais especialmente, na classe média do país. Nesta religião, a iniciação não se dá sem que o indivíduo esteja em contato com um "grupo de estudos" e orientações de leitura. Ora, é preciso considerar o fato de que a religião fundada por Alan Kardec é cercada por um comércio de literatura especializada. Para concluir esta primeira parte, Carlos Alberto Steil ${ }^{6}$ descreve o seu trabalho de campo sobre o santuário do Bom Jesus da Lapa, local de peregrinação católica situado no interior do estado da Bahia. Ele revela uma peregrinação renovada e profundamente ligada à realidade social do país. Estes fiéis encontram na religião uma forma de exacerbação do descontentamento com a política nacional.

$\mathrm{Na}$ segunda parte da obra, a mesma trilogia de análise (a linguagem, a cultura e a identidade) foi adaptada à "Realidade Francesa". No primeiro capítulo, Jean-Marc Lavaur $^{7}$ apóia-se sobre os estudos de psicologia cognitiva para tentar compreender os indivíduos bilíngües. Em geral, estes conseguem adaptar-se à dois sistemas simbólicos diferentes sem que haja um conflito interno. Este autor ressalta a importância de um maior investimento governamental na política linguística francesa. A seguir, Claude Llena ${ }^{8}$ aborda a dificuldade dos indivíduos à margem da sociedade que, por vezes, perdem sua identidade e seus referenciais. Estas pessoas podem ser reintegradas à vida social através do apoio de redes de trocas recíprocas de conhecimentos. A autora cita os trabalhos dos Réseaux d'Echanges Réciproques de Savoirs (os R.E.Rs, Redes de Trocas Recíprocas de Conhecimentos), um projeto de educação popular destinado às pessoas que não foram beneficiadas por uma educação clássica. Estes grupos têm por base os princípios de pluralidade, de paridade e de desmonetarização das relações sociais, permitindo, assim, a troca de conhecimentos clássicos ou funcionais, de savoir-faire. Tais grupos favorecem o altruísmo e as alianças objetivando que os indivíduos reencontrem sua auto-estima perdida dentro do grupo para, num segundo momento, poderem estabelecer vínculos exteriores ao grupo. Em seguida, Jean-François Hamon ${ }^{9}$ retraça a história da Ilha da Reunião para poder associar a diversidade cultural e linguística à identidade local. A língua crioula é uma forma de língua diretamente ligada à expressão emocional. Neste sentido, a lín- 
gua francesa seria, pelo contrário, uma forma de expressão da racionalidade. Este relato mostra a diferença de tratamento dos bilíngües em relação às línguas adquiridas.

O capítulo seguinte é dedicado por Mohand Khellil ${ }^{10}$ à mulher magrebina na França. $\mathrm{O}$ autor explora o dualismo dos mecanismos de integração destas mulheres à uma cultura diferente e, ao mesmo tempo, os laços que elas conseguem manter com sua cultura original. $\mathrm{O}$ desfecho deste livro se faz com o texto do psicólogo Mohamed Ham ${ }^{11}$, que aborda as situações de exílio. Ele retoma a questão da língua, afirmando que a reconstrução da identidade do indivíduo exilado passa por uma reapropriação da língua primeira e do seu sentido mais profundo. Do ponto de vista da psiquê humana, o exílio é vivido como um vôo livre, onde aquele que o segue deve despojar-se de tudo para entregar-se ao desconhecido.

Linguagem, cultura e identidade. Três conceitos que relatam como se constituem as sociedades e sobre que bases estas evoluem. Além de ser uma particularidade cara a qualquer organização humana, esta infra-estrutura segue paulatinamente uma dinâmica de dádiva e contra-dádiva na pluralidade das organizações sociais que coabitam o planeta •

\section{Notas}

MEDEIROS, João; LAVAUR, Jean-Marc. Réalités françaises et brésiliennes. Langages, cultures et identités. Montpellier: UPV, 2005, Tome I, $294 \mathrm{p}$.

1 João Medeiros, Sociologia, Montpellier.

2 Ruben George Oliven, Antropologia, Universidade Federal do Rio Grande do Sul.

3 Airton Luiz Jungblut, Antropologia, PUCRS de Porto Alegre.

4 Isabel C. Moura, Psicologia, Universidade Luterana do Rio Grande do Sul.
5 Bernardo Lewgoy, Antropologia, Universidade Federal do Rio Grande do Sul.

6 Carlos Alberto Stell, Universidade Federal do Rio de Janeiro.

7 Jean-Marc Lavaur, Psicologia, Universidade Paul Valéry - Montpellier III.

8 Claude Llena, Sócio-economia, Ecole polytechnique, Université Montpellier II.

9 Jean-François Hamon, Psicologia, Universidade da Réunion.

10 Mohand Khellil, Sociologia, Universidade Paul Valéry Montpellier III.

11 Mohamed Ham, Psicologia, Universidade de Nice Sophia Antipolis. 